\title{
Reflections
}

\section{Lectio praecursoria: Theory of control tuning - the processing of control in migration-related place coping}

\author{
SAIJA NIEMI
}

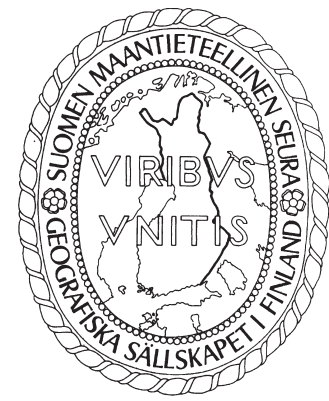

Niemi, S. (2019) Lectio praecursoria: Theory of control tuning - the processing of control in migration-related place coping. Fennia 197(1) 163-167. https://doi.org/10.11143/fennia.79471

In this lectio praecursoria, which I presented as part of my doctoral defence at the University of Helsinki on 26 October 2018, I introduce a new migration-related control theory that I developed in my doctoral research. The theory of control tuning is a middle-range theory that closes the gap between empirical data and formal theory. The theory is mainly based on primary data from South Sudanese migration, which I brought from the descriptive level to the conceptual level by using classic grounded theory methodology. The theory of control tuning explains how various migration actors process control in their everyday life in order to manage and govern feelings, information, actions and people as well as ownership of situations and objects. Control tuning refers to the action of modifying control, and it occurs through particular control-tuning paths. These control-tuning paths consist of control-tuning causes, strategies, outcomes, intervening factors and conditions. Control-tuning paths appear in relation to the behavioural arena of migration. This behavioural arena includes the elements, circumstances, relationships and objects of the physical, social, political, cultural and economic world with which migration actors come into contact and interact. The main activities in the behavioural arena of migration are place coping, knowledge dealing, encountering authority and link keeping. The theory of control tuning demonstrates that control tuning occurs regardless of whether migration is international or internal or forced or voluntary and irrespective of the status of a migrant, or whether the actor is a local resident or an authority, or whether migration actors move or stay put. Moreover, the theory of control tuning demonstrates that control has significance for individuals and groups of migration actors.

Keywords: control tuning, control, migration, place, grounded theory, South Sudanese migration

Saija Niemi, Helsinki Institute of Urban and Regional Studies, University of Helsinki, Yliopistonkatu 3, P.O. Box 4, 00014 University of Helsinki, Finland. E-mail: saija.niemi@helsinki.fi

Mr Custos, Madam Opponent, ladies and gentlemen:

The Spanish sociologist Joaquín Arango $(2000,295)$ remarks: "Perhaps the greatest difficulty of studying migration lies in its extreme diversity, in terms of forms, types, processes, actors, motivations, 
socio-economic and cultural contexts, and so on. It is no wonder that theories are at odds when trying to account for such complexity."

In turn, another sociologist, Adrian Favell $(2008,260)$ comments: "There could hardly be a topic in the contemporary social sciences more naturally ripe for interdisciplinary thinking than migration studies." Favell also calls for a renewal of the conceptual tools with which we think about and recognise migration.

Migration-related research has long lacked up-to-date theories that would provide us with both a novel understanding of the diversity of migration and new concepts to use when talking about and researching migration. Migration researchers seem to have been somewhat reluctant to theorise migration due to a general call for an all-encompassing migration theory that would include everything there is in the phenomenon. Some researchers have indeed considered constructing a theory that would synthesise existing migration theories into one, all-explaining theory. By contrast, other migration researchers have considered this an impossible and potentially futile task. Attempts to theorise the complex phenomenon of migration have often failed, and it seems most researchers have thus abandoned the attempt. Conversely, an increasing amount of migration research has been conducted at the descriptive and empirical level.

Migration research has also been strongly characterised by binary thinking, such as international versus internal, agency versus structure, micro versus macro and forced versus voluntary. This has somewhat hampered theory formation, as researchers have struggled to theorise such extreme concepts with descriptive data and inadequate methodologies.

My doctoral study (Niemi 2018) has four aims. The main aim is to understand the common main concern of various actors in migration, regardless of its type, nature and geographical area. The second aim is to close the gap between empirical data and formal theory by generating a new middlerange migration theory. The third aim is to advance research in the field of migration, geography, social sciences and grounded theory methodology, and in any other discipline relevant to the new theory. Finally, the fourth aim is to explore the possibilities for multidisciplinarity and interdisciplinarity in the mentioned disciplines through a genuinely multi- and interdisciplinary grounded theory.

I have provided science and practice with a new theory called the theory of control tuning, which allows us to see migration from a fresh perspective. When I began the study, I had no idea that I would be studying control and migration for the many years to come. Unlike the often-used approach of starting with particular research questions and ready hypotheses, I began with an interest in understanding the similarities between different actors involved in migration, such as asylum seekers, internally displaced persons, recognised refugees, education- and employment-induced migrants, those migrating for other personal reasons, local residents and authorities linked to migration. I wanted to hear what all these actors considered important rather than starting from a literature review to see what other researchers had done and what they had thought to be significant. I wanted to see if there were similarities rather than differences.

Consequently, I adopted classic grounded theory as my methodology and embarked on fieldwork in several geographical areas in Finland, Egypt, Uganda and Sudan. At that point, South Sudan did not yet exist as an independent state. However, I was particularly interested in investigating South Sudanese migration, as it is geographically extensive and covers different types of migration actors and migration movements. South Sudanese migration provides information on asylum-seeking occurring due to a conflict within a state and while migrating to neighbouring countries and other continents, migration for education and employment purposes and for other personal reasons, and quota refugees and return migration to different types of places. Moreover, South Sudanese migration involves many organisations and authorities as well as local residents from a variety of places, which was significant for understanding the behaviour of various migration actors.

I conducted interviews, discussions and observations in camps for the internally displaced, refugee settlements, border towns, urban centres, rural areas, the homes of local residents and the offices of authorities. At times, the fieldwork was dangerous and mentally and physically exhausting due to working in environments of conflict and violence, in areas with challenging infrastructure and among people with severe mental and physical health issues. Many of the interviewees had experiences of fleeing, being raped, being tortured, witnessing a murder and other horrible events. Some authorities 
had mistreated migrants, while some felt despair about being unable to help them. By contrast, some local residents were upset about being surrounded by such different cultures and people with different ways of behaviour; however, others enjoyed meeting new people from far-away places.

In the interviews of migrants with different statuses, my main question was "Can you please tell me about your migration experiences?" This question was designed to "instil a spill", that is to give the interviewees a chance to discuss anything they wanted, thereby allowing me to see what was important to them. In turn, with authorities, the interviews were often more formal, and with local residents the nature of the interview depended on the interviewee.

I recorded the fieldwork data as field notes and research diaries. In addition, I also used secondary data, such as maps, statistics, photos and the literature. In grounded theory methodology, one of the most important actions is to memo one's ideas and use those memos as the backbone of a new theory. Through the procedure of open and selective coding, constant comparison, memoing, sorting and theoretical coding, I was able to bring the primary and secondary data from the descriptive level to the conceptual level. In addition to the new theory, the study also offers several new concepts for the migration lexicon, concepts such as control tuning, place picking, emotional ride, dividing space and okaying.

The theory of control tuning explains the main concern - the processing of control - of migration actors in relation to the aspects of their lives affected by migration. In this study, control is understood in broad terms and includes tactics and strategies for managing and governing feelings, actions, information and people as well as ownership of situations and objects. The theory demonstrates how migration actors resolve challenges related to control by control tuning in connection with a behavioural arena that consists of activities like place coping, knowledge dealing, encountering authority and link keeping. Behaviour that occurs in relation to place, knowledge, authority and linking with others produces control situations that require actors to process the control that they themselves or others possess and use and the control that they face through the behaviour of others. The theory of control tuning has two important foci: control-tuning paths, which explain how control is processed, and the behavioural arena of migration, which demonstrates what control is processed in relation to.

The concept of control tuning refers to the action of modifying control for different purposes in relation to managing events, situations, feelings, objects and people during and in relation to migration. Control can be acceptable, unpleasant or insignificant from the viewpoint of the actors concerned. Therefore, control is processed in different ways depending on its importance and the situation or situations where it appears. Control tuning occurs due to what is often a series of control situations that generate particular control-tuning paths.

Control-tuning paths consist of control-tuning causes, strategies, outcomes and intervening factors and conditions. In the data, I identified control-tuning causes such as the need to accept control, wanting to force control and the need to increase control; I found control-tuning strategies such as sharing control, handing over control and dealing with obstructing control; and I discovered control-tuning outcomes such as fluctuating control, gained control and non-existent control.

On these control-tuning paths, causes for migration actors to react to their own or others' control arise. Thus, these actors adopt a strategy or strategies in order, for instance, to promote or hinder their own or others' control to reach an outcome that they consider appropriate. However, even if migration actors, either consciously or subconsciously, aim to reach a suitable level or degree of control, they may not always achieve to the desired degree. When migration actors intend to change or maintain the control situation but the outcome is unsatisfactory, they may adopt a different strategy or strategies, or remain with the same strategy in an attempt to process control and transform the control situation.

Control situations are affected by several intervening factors that modify the control-tuning paths, thus influencing the need for a particular strategy or strategies. Intervening factors can be control supportive or control preventing. In the theory of control tuning, the intervening factors are divided into three categories: basic factors such as age, sex, ethnicity and appearance, varying factors such as gender roles, health and personal skills, and control supportive instruments such as various means and abilities, for instance means of communication and the ability to forgive. 
A control-tuning outcome appears at the end of a control-tuning path. However, as many controltuning paths appear simultaneously, even if one control-tuning path ends, others are often still pursued and new ones begin. Control tuning occurs when there is dissatisfaction and a negative condition, and only when migration actors experience a positive condition, that is when they are successful and/or satisfied in the processing of control, is there no need to seek a strategy or strategies for further processing control by control tuning. Migration actors process control by control tuning while both traveling through various environments and remaining in spaces and places.

Control-tuning paths appear in relation to the behavioural arena of migration. The behavioural arena of migration explains what migration actors process control in relation to. The behavioural arena includes the elements, circumstances, relationships and objects of the physical, social, political, cultural and economic world with which migration actors come into contact and interact. Link keeping, encountering authority, knowledge dealing and place coping, which are the main activities in the behavioural arena of migration, all contain other sub-activities and their properties.

In my dissertation, I introduce place coping in more detail. Multi routing, place sensing, spatial manoeuvring, establishing a new normal, re-rooting home and problem confronting are all important aspects of place coping. I also illustrate practical incidents of place coping by taking the theory back to its roots to the empirical data. This is an experimental twist in the use of grounded theory methodology.

In grounded theory studies, the researcher does not attempt to verify the work of others; rather the new theory is synthesised with what already exists in relation to it. In my dissertation, I demonstrate how the theory of control tuning relates to and provides new perspectives for the research and conceptualisation of control, space and place, and migration. In addition, I show how the theory of control tuning connects and contributes to research and concepts of migration-related central binaries, grounded theory studies, multidisciplinarity and interdisciplinarity. I also demonstrate how my study strengthens knowledge on conducting demanding data collection and fieldwork. Even though grounded theory methodology does not contain any epistemological or ontological positions per se - as it stands firmly on its own as a methodology - I present the study's interfaces with phenomenological and hermeneutical philosophies as a loose philosophical framework. I also position the study within the disciplinary context of humanistic geography. I conclude the dissertation by discussing the achievement of the research aims, the limitations of the study and the possibilities for future research. I also reflect on my personal learning and share practical and policy recommendations.

I believe that my study and the theory of control tuning contribute to science and practice in important ways. The new theory is able to place, within one theory, a behavioural pattern that occurs in migration irrespective of the status or type of migration actor, the internal or international nature of migration or the direction of migration between rural and urban areas. Moreover, the theory demonstrates that control tuning occurs in all types of migration movements and also while staying put, regardless of the voluntary or forced nature of that migration.

The theory also reveals that space and place are not losing their meaning in migration, quite the contrary. In fact, space and place are highly significant and appear as both migration-related actions and characteristics. Coping in different kinds of spaces and places is one of the most important activities that generate control-tuning paths. The theory of control tuning contributes to both theoretical and conceptual knowledge through presenting novel, previously unseen connections and new vocabulary. Furthermore, the theory has fit, relevance and grab. I present a theory which demonstrates that rather than viewing control and migration from the common migration management perspective where states and international alliances control migration in their geographical areas, control should be understood as a crucial aspect of the everyday life of individuals and groups.

As I mentioned earlier, a grounded theory study does not begin with a hypothesis. Rather, it is only possible to form a hypothesis after a new theory has been developed. Thus, I end my presentation, as I ended my study, with the hypothesis of the research: "The main concern of migration actors is the processing of control, which they resolve on a continuous basis by control tuning in the behavioural arena of migration, regardless of the nature, type, length, geographical area, actors, time, level and life sphere of that migration." It is now the task of others to determine how they view and use the theory of control tuning. I look forward with great interest to seeing how the theory shows its strength in both academia and practice. 


\section{References}

Arango, J. (2000) Explaining migration: a critical view. International Social Science Journal 52(165) 283296. http://doi.org/10.1111/1468-2451.00259

Favell, A. (2008) Rebooting migration theory: interdisciplinarity, globality, and postdisciplinarity in migration studies. In Brettell, C. B. \& Hollifield J. F. (eds.) Migration Theory: Talking Across Disciplines, 259-278. Routledge, New York.

Niemi, S. (2018) Theory of control tuning: the processing of control in migration-related place coping. Department of Geosciences and Geography A66. Painosalama Oy, Turku. https://helda.helsinki. fi/handle/10138/247811?locale-attribute=en 